\title{
ANALISIS LOYALITAS PELANGGAN SMARTPHONE MEREK SAMSUNG GALAXY J5 PRO DI KABUPATEN PRINGSEWU
}

\author{
Desi Derina Yusda \\ Program Studi D3 Manajemen Industri \\ Fakultas Bisnis Universitas Mitra Indonesia \\ Email: desiderina@umitra.ac.id
}

\begin{abstract}
Advertising and brand image are important factors in creating positive and good Customer Loyalty for a product. Advertising and brand image become a banchmark of the success of a company where as successfully applying the four things will affect customer loyalty and can increase sales so that the achievement of a company's goal is profit and not forget to pay attention to the interests of consumers loyal to the product offered by the company. The purpose of this study is to describe the influence of advertising and brand image of customer loyalty. This study uses a sample of Samsung Galaxy J5 Pro smartphone users in Pringsewu, Lampung with as many as 60 respondents. Sampling technique using Snowball Sampling method. The data analysis method used is multiple linear regression. The results of this study indicate that advertising have a significant effect on customer loyalty, while brand image has no significant effect on customer loyalty.
\end{abstract}

Keywords: Advertising, Brand Image, Customer Loyalty.

\section{PENDAHULUAN}

\subsection{Latar Belakang}

Perkembangan media teknologi komunikasi di Indonesia saat ini semakin canggih. Seperti semakin banyaknya masyarakat yang menggunakan media komunikasi. Industri mobile semakin berkembang pesat, pasalnya semakin hari semakin banyak gadget canggih untuk menunjang kebutuhan penggunanya. Secara umum, sebuah smartphone biasanya memiliki fitur yang canggih, terlebih jika sudah dibekali dengan sistem operasi seperti android, windows phone ataupun iOS.

Keseriusan perusahaan smartphone dalam mengeksplorasi pasar dapat dilihat dari berbagai penawaran yang diberikan perusahaan dan banyaknya merek yang bermunculan membuat konsumen memiliki banyak pilihan untuk membeli produk smartphone. Keputusan dalam membeli timbul dalam pikiran konsumen karena didasarkan pada informasi-informasi yang telah diketahui oleh konsumen dan konsumen memiliki ketertarikan pada produk smartphone seperti smartphone Samsung. $\begin{array}{ccc}\text { Perusahaan } & \text { Samsung dalam } \\ \text { memasarkan produk } & \text { smartphone } & \text { yang }\end{array}$ diproduksi menggunakan beberapa cara agar ponselnya laku dipasaran salah satunya dengan memasang iklan. Menurut Kotler dan Armstrong (2012 : 454) iklan adalah segala bentuk penyajian dan promosi ide, barang atau jasa secara nonpersonal oleh suatu sponsor tertentu yang memerlukan pembayaran. Dengan memakai beberapa artis sebagai brand ambassador produknya. Pada suatu merek dapat mempengaruhi konsumen loyal dengan merek tersebut jika artis yang dipakai memiliki citra baik, selain itu juga meningkatkan penjualan suatu produk dan dengan mudah menyampaikan pesan kepada konsumen mengenai suatu produk. Stategi ini dibilang sangat berhasil karena mendapat perhatian dari masyarakat. Penjualan smartphone yang menggunakan artis sebagai brand ambassador ini meningkat cukup pesat. Selain itu brand tersebut menjadi lebih dikenal oleh banyak masyarakat.

Minat konsumen dengan smartphone Samsung di Indonesia mengalami peningkatan. Dari data yang peneliti dapatkan di Top Brand 
Award smartphone Samsung menduduki peringkat pertama dari tahun 2015,2016 , dan
2017 dan ini dapat terlihat dari tabel Top Brand Award sebagai berikut :

Tabel 1.

Top Brand Award Smartphone Fase 1 2015, 2016, 2017.

\begin{tabular}{|c|c|c|c|c|c|c|c|c|}
\hline \multicolumn{3}{|c|}{2015} & \multicolumn{3}{|c|}{2016} & \multicolumn{3}{|c|}{2017} \\
\hline MEREK & TBI & TOP & MEREK & TBI & TOP & MEREK & TBI & TOP \\
\hline Samsung & $29,7 \%$ & TOP & Samsung & $43,4 \%$ & TOP & Samsung & $46,4 \%$ & TOP \\
\hline Blackberry & $24,7 \%$ & & Nokia & $10,9 \%$ & & Nokia & $8,8 \%$ & \\
\hline Nokia & $16,7 \%$ & & Blackberry & $9,8 \%$ & & Blackberry & $8,0 \%$ & \\
\hline iPhone & $4,5 \%$ & & Iphone & $5,8 \%$ & & iPhone & $5,1 \%$ & \\
\hline Smartfren & $3,8 \%$ & & Smartfren & $5,4 \%$ & & Smartfren & $5.1 \%$ & \\
\hline Cross & $3,0 \%$ & & Lenovo & $4,0 \%$ & & Lenovo & $4,4 \%$ & \\
\hline Advan & $2,9 \%$ & & Oppo & $3,4 \%$ & & Oppo & $4,1 \%$ & \\
\hline Mito & $2,5 \%$ & & Asus & $3,2 \%$ & & Asus & $3,8 \%$ & \\
\hline Lenovo & $2,4 \%$ & & & & & & & \\
\hline Oppo & $2,2 \%$ & & & & & & & \\
\hline
\end{tabular}

Sumber : http://www.topbrand-award.com/.2018

Samsung Galaxy J5 Pro adalah smartphone dari samsung yang memiliki spesifikasi andalan berupa prosesor octa-core, selain itu salah satu keunggulan lainnya adalah smartphone ini memiliki kamera depan yang mirip dengan keunggulan Samsung yaitu Samsung Galaxy S8 dan kameranya mampu memberi kecerahan yang lebih baik di kondisi kurang cahaya, kamera depannya pun bisa membuat selfie lebih cerah, dengan LED flash khusus untuk selfie. Smartphone ini tampil dengan desain indah dengan balutan material metal dan kaca yang menambah daya tarik lebih mewah dan elegan dengan desain yang begitu menarik dan akan memberi kepercayaan lebih pada konsumen dan desainnya mirip dengan Samsung Galaxy S7, smartphone Samsung Galaxy J5 Pro ini memiliki banyak kelebihan dari Samsung sebelumnya membuat konsumen tertarik untuk beralih ke smartphone Samsung Galaxy J5 Pro.

Loyalitas didefinisikan sebagai suatu sikap yang ditujukan oleh konsumen terhadap penyediaan produk atau jasa. Seorang konsumen menunjukan loyalnya jika suatu perusahaan mampu memberikan kepuasan kepada konsumennya. Konsumen yang loyal adalah seorang konsumen yang selalu membeli kembali dari provider atau penyedia jasa yang sama dan memelihara suatu sikap positif terhadap penyedia jasa itu dimasa yang akan datang Griffin (2007:4).

Selain iklan, menurut Kotler dan Keller (2012:263-264) citra merek adalah "Perception and beliefs held by consumer. As reflected in the associations held in consumer memory." Maksud dari kalimat diatas adalah konsumen akan menganut persepsi dan kepercayaan sesuai dengan pengalaman yang telah mereka rasakan dan terangkum dalam ingatan mereka. Citra merek di mata para konsumen semakin baik citra merek yang diciptakan produk, maka secara tidak langsung konsumen dengan mudah akan loyal dengan merek tersebut.

Citra merek juga berkaitan dengan kualitas produk adalah kemampuan suatu produk dalam memberikan kinerja sesuai dengan fungsinya. Kualitas yang sangat baik membangun kepercayaan konsumen sehingga merupakan penunjang kepuasan konsumen (Kotler, 2012:225). Semakin baik kualitas yang dimiliki oleh suatu produk maka hal tersebut akan berpengaruh terhadap loyalitas konsumen akan produk yang ditawarkan sehingga tidak dipungkiri konsumen akan tertarik untuk melakukan pembelian ulang produk tersebut.

Selain itu citra merek juga berkaitan dengan harga, harga adalah jumlah uang yang harus dibayar pelanggan untuk produk itu (Philip Kotler, 2012:132). 


\subsection{Perumusan Masalah}

1. Apakah iklan mempengaruhi loyalitas pelanggan pada produk Smartphone merek Samsung Galaxy J5 Pro di Kelurahan Pringsewu Barat.

2. Apakah citra merek mempengaruhi loyalitas pelanggan pada produk Smartphone merek Samsung Galaxy J5 Pro di Kelurahan Pringsewu Barat?

3. Apakah iklan dan citra merek mempengaruhi loyalitas pelanggan pada produk Smartphone merek Samsung Galaxy J5 Pro Di Kelurahan Pringsewu Barat.

\subsection{Tujuan Penelitian}

1. Untuk mengukur besarnya pengaruh iklan terhadap loyalitas pelanggan pada produk Smartphone merek Samsung Galaxy J5 Pro di Kelurahan Pringsewu Barat.

2. Untuk mengukur besarnya pengaruh citra merek terhadap loyalitas pelanggan pada produk Smartphone merek Samsung Galaxy J5 Pro di Kelurahan Pringsewu Barat.

3. Untuk mengukur besarnya pengaruh iklan dan citra merek terhadap loyalitas pelanggan pada produk Smartphone merek Samsung Galaxy J5 Pro Di Kelurahan Pringsewu Barat.

\section{TINJAUAN PUSTAKA}

\subsection{Periklanan}

Menurut Kotler dan Armstrong (2012 : 454) iklan adalah segala bentuk penyajian dan promosi ide, barang atau jasa secara nonpersonal oleh suatu sponsor tertentu yang memerlukan pembayaran.Tujuan Periklanan Tjiptono (2011:41) berpendapat bahwa iklan memiliki tiga tujuan utama, yaitu meng informasikan produk yang ditawarkan dan menciptakan permintaan awal, membujuk dan mempengaruhi konsumen untuk membeli produk yang ditawarkan, serta mengingatkan konsumen mengenai keberadaan suatu produk serta berupaya melekatkan nama atau merek produk tertentu kepada konsumen.

Periklanan merupakan salah satu tahap dalam pemasaran. Produk barang atau jasa, baik penamaannya, pengemasannya, penetapan harga, dan distribusinya tercermin dalam kegiatan periklanan. Tanpa periklanan, berbagai produk tidak akan dapat mengalir secara lancar ke para distributor atau penjual, apalagi ke tangan konsumen (Suyanto, 2014:1).

\subsection{Citra Merek}

Kotler dan Keller (2012:263) mengungkapkan bahwa "Merek adalah produk atau jasa yang dimensinya mendiferensikan merek tersebut dengan beberapa cara dari produk atau jasa lainnya yang dirancang untuk memuaskan kebutuhan yang sama. Perbedaan ini bisa fungsional, rasional, dan nyata, berhubungan dengan kinerja produk dari merek. Perbedaan ini bisa lebih bersifat simbolis, emosional, atau tidak nyata, berhubungan dengan apa yang dipresentasikan oleh merek."

Menurut Kotler dan Keller (2012:274), pengertian citra adalah cara masyarakat menganggap merek secara aktual. Agar citra dapat tertanam dalam pikiran konsumen, pemasar harus memperlihatkan identitas merek melalui saran komunikasi dan kontak merek yang tersedia. Citra merek merupakan persepsi masyarakat terhadap perusahaan atau produknya. Citra dapat terbentuk melalui rangsangan yang datang dari luar sebagai seuatu pesan yang menyentuh atau disebut informasi yang diterima seseorang. Citra merek adalah persepsi masyarakat terhadap perusahaan atau produknya.

Kotler dan Keller (2012:263-264) mengemukakan difinisi citra merek yaitu "Perception and beliefs held by consumer. As reflected in the associations held in consumer memory." Maksud dari kalimat diatas adalah konsumen akan menganut persepsi dan kepercayaan sesuai dengan pengalaman yang telah mereka rasakan dan terangkum dalam ingatan mereka.

\subsection{Loyalitas Pelanggan}

Menurut Kotler dan Keller (2012:138) loyalitas adalah komitmen yang dipegang secara mendalam untuk membeli atau mendukung kembali produk atau jasa yang disukai dimasa depan meski pengaruh 
situasi dan usaha pemasaran berpotensi menyebabkan pelanggan beralih.

Menurut Tjiptono (2011:110) menyatakan bahwa loyalitas pelanggan sebagai komitmen pelanggan terhadap suatu merek, toko, pemasok berdasarkan sikap yang sangat positif tercermin dalam pembelian ulang yang konsisten.Dari kedua definisi loyalitas diatas maka dapat disimpulkan bahwa konsep loyalitas lebih mengarah pada perilaku (behavior) dibandingkan dengan sikap (attitude) dan seorang konsumen yang loyal akan memperlihatkan perilaku pembelian yang didefinisikan sebagai pembeli yang teratur dan memperlihatkan sepanjang waktu oleh beberapa unit pembuat keputusan. Tujuan utama atau misi perusahaan adalah mencapai tingkat loyalitas yang tinggi dari konsumen. Hal ini dikarenakan dengan mendapatkan sikap loyalitas dari konsumen berarti perusahaan dihadapkan kepada keuntungan ditambah lagi apabila penerapan dalam jangka panjang, maka sudah dapat dipastikan bahwa perusahaan akan menerima keuntungan jangka panjang pula.

\subsection{Hipotesis}

$\mathrm{H} 1$ : Diduga iklan berpengaruh terhadap loyalitas pelanggan pada produk smartphone merek Samsung Galaxy J5 Pro di Kelurahan Pringsewu Barat

$\mathrm{H} 2$ : Diduga citra merek berpengaruh terhadap loyalitas pelanggan pada produk smartphone merek Samsung Galaxy J5 Pro di Kelurahan Pringsewu Barat

H3 : Diduga iklan dan citra merek berpengaruh terhadap loyalitas pelanggan pada produk smartphone merek Samsung Galaxy J5 Pro di Kelurahan Pringsewu Barat

\section{METODE PENELITIAN}

\subsection{Jenis Penelitian}

Jenis penelitian yang digunakan untuk penelitian ini adalah penelitian korelasional dan survey untuk mengetahui hubungan antara iklan dan citra merek berpengaruh terhadap loyalitas pelanggan pada produk smartphone merek Samsung Galaxy J5 Pro di Kelurahan
Pringsewu Barat. Dalam penelitian ini uji yang digunakan meliputi, uji reliabilitas, uji validitas, analisis regresi, uji signifikasi serta uji koefisien determinasi. Penelitian di laksanakan peneliti di Kabupaten Pringsewu tepatnya, Kelurahan Pringsewu Barat, Pringsewu.

\subsection{Populasi Dan Sampel}

Populasi menurut Anwar Sanusi (2012:87) adalah seluruh kumpulan elemen yang menunjukkan ciri-ciri tertentu yang dapat digunakan untuk membuat kesimpulan. Kumpulan elemen itu akan menunjukkan jumlah, sedangkan ciri-ciri menunjukkan karakteristik dari kumpulan tersebut. Populasi dalam penelitian ini adalah konsumen yang mempunyai smartphone Samsung Galaxy J5 Pro di Kelurahan Pringsewu Barat, Kecamatan Pringsewu Kab. Pringsewu, Lampung.

Menurut Sugiyono (2014:81) Sampel adalah bagian dari jumlah dan karakteristik yang dimiliki oleh populasi tersebut. Bila populasi besar dan peneliti tidak mungkin mempelajari semua yang ada pada populasi, misalnya karena keterbatasan dana, tenaga dan waktu, maka peneliti dapat menggunakan sampel yang diambil dari populasi itu.

Dengan menggunakan teknik Nonprobability Sampling. Dalam penelitian ini teknik yang diambil menggunakan teknik Snowball Sampling. Menurut Sugiyono (2012:97) Snowball Sampling adalah teknik penentuan sampel yang mula-mula jumlahnya kecil, kemudian membesar. Ibarat bola salju yang lama lama menjadi besar. Dalam penentuan sampel, pertama-tama dipilih satu orang (key information) yang memakai smartphone Samsung Galaxy J5 Pro di wilayah Keluraham Pringsewu Barat yang bernama Sekar Ayuputri M.S yang masih duduk dibangku SMA selanjutnya Sekar memberikan informasi bahwa ada temannya juga yang bernama Olda Januansa teman sekolahnya yang tinggal di wilayah Kelurahan Pringsewu Barat memakai smartphone Samsung Galaxy J5 Pro, tetapi dengan dua orang ini belum merasa lengkap terhadap data yang diberikan, maka peneliti terus mencari orang lain yang dipandang lebih tahu dan dapat melengkapi data yang diberikan dari dua orang 
sebelumnya. Begitu seterusnya sehingga jumlah sampel menjadi lebih banyak. Berdasarkan pendapat diatas maka peneliti membatasi sampel yang dijadikan penelitian yaitu sebanyak 60 konsumen yang mempunyai smartphone Samsung Galaxy J5 Pro di Kelurahan Pringsewu Barat, Kecamatan Pringsewu, Kab. Pringsewu, Lampung.

\subsection{Teknik Pengumpulan Data}

Teknik pengumpulan data berupa survei untuk pendekatan kuantitatif dan wawancara untuk pendekatan kualitatif, dalam pendekatan kuantitatif instrumen yang digunakan adalah berupa kuesioner yang di bagikan kepada konsumen yang mempunyai Smartphone Samsung Galaxy J5 Pro di Kelurahan Pringsewu Barat Kecamatan Pringsewu , Kab. Pringsewu, Lampung, sedangkan dalam pendekatan kualitatif instrumen yang digunakan adalah data wawancara dengan mewawancarai konsumen yang mempunyai smartphone Samsung Galaxy J5 Pro di Kelurahan Pringsewu Barat, Kecamatan Pringsewu , Kab.Pringsewu, Lampung, wawancara dilakukan untuk memperoleh pemahaman yang luas dan lebih baik tentang fenomena yang ada pada konsumen yang memiliki smartphone Samsung Galaxy J5 Pro di Kelurahan Pringsewu Barat.

\subsection{Teknik Analisis Data}

Penelitian yang digunakan dalam penelitian ini adalah penelitian deskriptif dengan pendekatan kuantitatif yaitu data yang diperoleh dari sampel populasi penelitian dianalisis sesuai dengan metode statistik yang digunakan dalam rangka memberikan gambaran secara sistematis yang berasal dari subjek atau objek penelitian. Dengan melakukan analisis statistik deskriptif, uji yang digunakan uji asumsi klasik dilanjutkan dengan uji regresi linier berganda dan uji hipotesis. Alat analisis dalam penelitian ini menggunakan SPSS versi 24.

\section{Uji Validitas dan Reliabilitas Data}

Dalam penelitian ini penulis mengukur Variabel $X_{1}$ yaitu Iklan, Variabel $X_{2}$ yaitu Citra Merek. Uji persyaratan instrumen dalam penelitian ini menguji Validitas. Uji validitas digunakan untuk menunjukan ukuran yang benar-benar apa yang hendak diukur (Sugiyono 2010) Dasar pengambilan keputusan adalah :

a) Jika $r_{\text {hitung }}>r_{\text {tabel }}$, maka butir atau pertanyaan tersebut valid.

b) Jika $r_{\text {hitung }} \leq r_{\text {tabel }}$, maka butir atau pertanyaan tersebut tidak valid.

Uji reliabilitas digunakan untuk mengetahui apakah alat pengukuran mempunyai kehandalan dalam mengukur Sugiono (2010). Apabila reability ciefficient (alpha) berkisaran antara 0,00-1,00 maka variabel dan butir pertanyaan yang diukur dapat dipercaya atau diandalkan untuk lebih jelas dapat dilihat dari tabel nilai Cronbach alpha (a) $>0.60$, dibawah ini :

Tabel 2.

Tingkat Keandalan Cronbach"s Alpha

\begin{tabular}{cc}
\hline $\begin{array}{c}\text { Nilai Cronbach's } \\
\text { alpha }\end{array}$ & Tingkat Keandalan \\
\hline $0.0-0.20$ & Kurang Andal \\
\hline$>0.20-0.40$ & Agak Andal \\
\hline$>0.40-0.60$ & Cukup Andal \\
\hline$>0.60-0.80$ & Andal \\
\hline$>0.80-1.00$ & Sangat Andal \\
\hline
\end{tabular}

Sumber : Sugiyono (2010)

\section{Asumsi Klasik}

Menurut Rambat Lupiyoadi dan Ridho Bramulya Ikhsan (2015:134-146) analisis regresi terdapat beberapa asumsi yang harus dipenuhi dehingga persamaan regresi yang dihasilkan akan valid jika digunakan untuk memprediksi suatu masalah. Model regresi linier, khususnya regresi berganda dapat disebut sebagai model yang baik jika model tersebut jika memenuhi kreteria.

\section{Uji Normalitas}

Uji normalitas dapat merupakan uji distribusi data yang akan dianalisis, apakah penyebaran normal atau tidak, sehingga dapat digunakan dalam analisis parametrik. Apabila data tidak berdistribusi normal, maka kita tidak dapat menggunakan analisis parametrik melainkan menggunakan analisis non-nomerik. 
Cara untuk menentukan apakah suatu model berdistribusi normal atau tidak, sebenarnya banyak cara yang dapat dilakukan untuk menentukan apakah data sudah mendistribusikan normal atau tidak. Digunakan dua pendekatan untuk menguji normalitas data.

\section{Uji Multikolinieritas}

Uji multikolinieritas untuk membuktikan atau menguji ada tidaknya hubungan yang linier antara variabel bebas (independen) satu dengan variabel bebas (independen) yang lainnya. Dalam analisis regresi berganda maka akan terdapat dua atau lebih variabel bebas atau variabel independen yang diduga akan mempengaruhi variabel tergantungnya. Pendugaan tersebut akan dapat dipertanggung jawabkan apabila tidak terjadi adanya hubungan yang linier diantara variabel-variabel independen.

\section{Uji Heteroskedasitas}

Uji Heteroskedastisitas digunakan untuk mengetahui ada atau tidaknya penyimpanan asumsi klasik heteroskedastisitas, adanya ketidaksamaan varian dari residual untuk semua pengamatan pada model regresi. Model regresi yang baik dan tidak terjadi masalah heteroskodastisitas. Dalam penelitian ini pendeteksi heterokedasrisitas digunakan uji spearman rho.

1. Ho : Tidak ada gejala heteroskodastisitas.

2. Ha : Ada gejala heteroskodastisitas.

3. Ho : Diterima apabila nilai signifikan antara variabel independen dengan residual lebih dari 0,05.

\section{Uji Autokorelasi}

Uji Autokorelasi bertujuan untuk menguji apakah model regresi ada kolerasi antara kealahan pengganggu pada waktu tertentu $\mathrm{t}$ (sekarang) dengan kesalahan pengganggu pada waktu tertentu $\mathrm{t}-1$ (sebelumnya). Apabila terjadi kolerasi, maka terdapat masalah autokolerasi. Untuk mendeteksi ada atau tidaknya autokolerasi maka dilakukan pengujian Durbin-Watson (DW) dengan ketentuan sebagai berikut :

1. $1,65<D-W<2,35$ maka tidak ada autokorelasi.
2. $1,21<D-W<1,65$ atau $2,35<D-W<$ maka tidak dapat disimpulkan.

3. $\mathrm{D}-\mathrm{W}<1,21$ atau $\mathrm{D}-\mathrm{W}>2,79$ maka terjadi autokorelasi.

\subsection{Pengujian Hipotesis}

1) $\mathrm{Uji} T$

Uji T dikenal dengan uji parsial, yaitu untuk menguji bagaimana pengaruh masingmasing variabel bebas secara sendiri-sendiri terhadap variabel terikatnya. Uji ini dapat dilakukan dengan membandingkan $\mathrm{T}$ hitung, proses uji $T$ identik dengan uji $F$ (lihat perhitungan SPSS pada Coeffient Regression Full Medel/Enter), atau bisa diganti dengan uji metode Stepwise.

\section{2) Uji F}

Hipotesis dalam uji $\mathrm{F}$ adalah sebagai berikut : Hipotesis mengenai ketetapan model. Ho : b1 = b2 = 0 (Pengambilan variabel X1 dan $\mathrm{X} 2$ tidak cukuptepat dalam menjelaskan variasi $Y$, ini berarti pengaruh variabel diluar model terhadap $\mathrm{Y}$, lebih kuat dibanding dengan variabel yang sudah dipilih. $\mathrm{Ha}: \mathrm{b} 1=\mathrm{b} 2=0$ (Pengambilan variabel $\mathrm{X} 1$ dan $\mathrm{X} 2$ sudah cukup tepat karena mampu menjelaskan variasi $Y$, dibanding dengan pengaruh variabel di luar model atau error terhadap $Y$ ) hasil $F$ hitung diatas sudah lebih besar dari 4, maka model yang memasukkan 2 variabel di atas sudah tepat. Jika $\mathrm{R}$ kuadrat merupakan perbandingan antara variasi $Y$ (variasi total) yang bisa dijelaskan oleh variabel penjelas, maka uji $F$ adalah perbandingan antara variasi $Y$ yang dapat dijelaskan.

\section{3) Uji Regresi Linier Berganda}

Analisis regresi linier berganda digunakan untuk mengetahui pengaruh Iklan dan Citra Merek terhadap Loyalitas Pelanggan. Selain itu juga analisis regresi linier berganda digunakan untuk menguji kebenaran hipotesis yang diajukan dalam penelitian ini. Persamaan regresi linier berganda yang akan digunakan adalah:

$Y=a+b_{1} X_{1}+b_{2} X_{2}+b_{3} X_{3}+b_{4} X_{4}+\varepsilon$ 


\section{4) Uji $\mathbf{R}^{2}$}

Uji $\mathrm{R}^{2}$ adalah perbandingan antara variasi $Y$ yang dijelaskan oleh $\mathrm{x} 1$ dan $\mathrm{X} 2$ secara bersama-sama dibanding dengan variasi total $Y$. Jika selain $x 1$ dan $x 2$ semua variabel di luar model yang diwadahi dalam $\mathrm{E}$ dimasukkan ke dalam model, maka nilai $\mathrm{R}^{2}$ akan bernilai 1 . Ini berarti seluruh variasi $Y$ dapat diperoleh dari banyak responden pada waktu yang sama, maka nilai $\mathrm{R}^{2}$ cenderung makin kecil. Sebaliknya dalam data namun runtun waktu dimana peneliti mengamati hubungan dari beberapa variabel pada satu unit analisis (perusahaan atau negara) pada beberapa tahun, maka $\mathrm{R}^{2}$ akan cenderung besar. Hal ini disebabkan variasi data relatif kecil pada runtun waktu yang terdiri dari satu unit analisis. Rumus $\mathrm{R}^{2}=\mathrm{KD}=\mathrm{R}^{2} \times 100 \%$

\section{HASIL PENELITIAN DAN PEMBAHASAN}

\subsection{Uji Pengaruh secara parsial}

Uji T digunakan untuk menguji secara parsial masing-masing variabel. Hasil uji $T$ dapat dilihat pada tabel coefficient pada kolom sig (significance). Jika probabilitas nilai $t$ atau signifikan < 0.05 maka dapat dikatakan bahwa terdapat pengaruh antara variabel bebas terhadap variabel terikat secara parsial.

Tabel 3.

Hasil Uji (Parsial) Coefficientsa

\begin{tabular}{|c|c|c|c|c|c|c|}
\hline \multirow{2}{*}{\multicolumn{2}{|c|}{ Model }} & \multicolumn{2}{|c|}{$\begin{array}{l}\text { Unstandardized } \\
\text { Coefficients }\end{array}$} & \multirow{2}{*}{$\begin{array}{c}\text { Standardized } \\
\text { Coefficients } \\
\text { Beta }\end{array}$} & \multirow[t]{2}{*}{$\mathrm{t}$} & \multirow[t]{2}{*}{ Sig. } \\
\hline & & $\mathrm{B}$ & Std. Error & & & \\
\hline \multirow{3}{*}{1} & (Constant) & .211 & .300 & & .702 & .486 \\
\hline & IKLAN & .299 & .110 & .323 & 2.715 & .009 \\
\hline & $\begin{array}{l}\text { CITRA } \\
\text { MEREK }\end{array}$ & -.120 & .114 & .133 & 1.044 & .301 \\
\hline
\end{tabular}

a. Dependent Variable: LOYALITAS

Sumber : output spss 24 (2018)

Berdasarkan tabel diatas coefficients dapat disimpulkan sebagai berikut :

1) Iklan (X1), Berdasarkan hasil penelitian dalam uji-t dapat disimpulkan bahwa variabel iklan (X1) diuji secara parsial menghasilkan perhitungan nilai $t_{\text {hitung }}$ sebesar $2.715>t_{\text {tabel }}$ sebesar 1.67 dan nilai sig sebesar $0.009<0.05$, maka dapat disimpulkan variabel iklan berpengaruh signifikan terhadapat variabel loyalitas pelanggan.

2) Citra Merek, Berdasarkan hasil penelitian dalam uji-t dapat disimpulkan bahwa variabel citra merek (X2) diuji secara parsial menghasilkan perhitungan nilai $t_{\text {hitung sebesar } 1.044<t_{\text {tabel }} \text { sebesar }}$ 1.67 dan nilai sig sebesar $0.301>0.05$, maka dapat disimpulkan variabel citra merek tidak berpengaruh signifikan terhadapat variabel loyalitas pelanggan.

\subsection{Uji F (simultan)}

Uji ini bertujuan untuk mengetahui pengaruh variabel bebas secara bersamasama (simultan) terhadap variabel terikat. Untuk melihat pengaruh bersama-sama dapat dilihat dengan membandingkan $\mathrm{F}$ tabel dengan $F$ hitung. Untuk lebih jelasnya dapat dilihat pada tabel Anova dibawah.

Berdasarkan pada tabel dibawah hasil uji $F$ (simultan) pada variabel independent menunjukan hasil nilai $F$ hitung sebesar 20.413 $>2.525 \mathrm{~F}$ tabel serta diperoleh nilai signifikan Sig $0.000<0.05$ maka dapat disimpulkan bahwa variabel iklan (x1), citra merek(x2) secara simultan berpengaruh terhadap variabel loyalitas pelanggan. 
Tabel 4.

Uji F (Simultan) ANOVAa

\begin{tabular}{lrrrrr}
\hline Model & Sum of Squares & df & Mean Square & F & \multicolumn{1}{c}{ Sig. } \\
\hline \multicolumn{1}{c}{ Regression } & 15.185 & 4 & 3.796 & 20.413 & $.000^{\mathrm{b}}$ \\
\cline { 2 - 7 } & 10.228 & 55 & .186 & & \\
\hline Residual & 25.413 & 59 & & & \\
\hline
\end{tabular}

a. dependent variable: loyalitas

b. predictors: (constant), iklan, citra merek

Sumber : output spss 24 (2018)

\subsection{Analisis Regresi Berganda}

Analisis regresi berganda digunakan

variabel bebas yaitu : iklan (X1) dan citra untuk mengetahui seberapa besar pengaruh merek $(\mathrm{X} 2)$, terhadap loyalitas pelanggan $(\mathrm{Y})^{\prime}$

Tabel 5.

Hasil Uji Regresi Linier Berganda Coefficientsa

\begin{tabular}{|c|c|c|c|c|c|c|}
\hline \multirow{2}{*}{\multicolumn{2}{|c|}{ Model }} & \multicolumn{2}{|c|}{$\begin{array}{l}\text { Unstandardized } \\
\text { Coefficients }\end{array}$} & \multirow{2}{*}{$\begin{array}{c}\text { Standardized } \\
\text { Coefficients } \\
\text { Beta }\end{array}$} & \multirow{2}{*}{$t$} & \multirow{2}{*}{ Sig. } \\
\hline & & $B$ & $\begin{array}{l}\text { Std. } \\
\text { Error }\end{array}$ & & & \\
\hline \multirow{3}{*}{1} & (Constant) & .211 & .300 & & .702 & .486 \\
\hline & IKLAN & .299 & .110 & .323 & 2.715 & .009 \\
\hline & $\begin{array}{l}\text { CITRA } \\
\text { MEREK }\end{array}$ & -.120 & .114 & .133 & 1.044 & .301 \\
\hline
\end{tabular}

a. Dependent Variable: LOYALITAS

Sumber : output spss 24 (2018)

Berdasarkan tabel 5 diatas terlihat bahwa nilai konstanta sebesar 0.211 dan koefesien b1 $0.299+$ b2 0.120 . Nilai konstanta dan koefesien regresi $(X 1, X 2)$ ini dimasukan dalam persamaan regresi berganda $Y=a+$ b1X1 + b2X2 + e

Sehingga persamaannya $Y=0.211+0.299 X 1$ $-0.120 \times 2$

1. Nilai Konstanta sebesar 0.211 hal ini menunjukan apabila variabel independent iklan ( X1) , citra merek (X2) tidak mengalami perubahan atau nilainya nol, maka dari variabel dependen Loyalitas Pelanggan $(Y)$ adalah sebesar 0.211 .

2. Iklan $(X 1)=0.299$

Merupakan nilai koefesien regresi variabel Iklan (X1) terhadap variabel Loyalitas Pelanggan (Y) artinya jika Iklan (X1) mengalami ditingkatkan $1 \%$, maka tingkat Loyalitas Pelanggan (Y) akan mengalami kenaikan sebesar 0.299 koefesien bernilai positif artinya antara Iklan (X1) dan Loyalitas $(Y)$ berhubungan positif.

3. Citra Merek $(X 2)=-0.120$

Merupakan nilai koefesien regresi variabel Citra Merek (X2) terhadap variabel Loyalitas Pelanggan $(Y)$ artinya jika Citra Merek (X2) mengalami ditingkatkan 1\%, maka tingkat Loyalitas Pelanggan (Y) akan mengalami kenaikan sebesar - 0.120 koefesien bernilai negatif artinya antara Citra Merek (X2) dan Loyalitas (Y) berhubungan negatif.

\subsection{Uji Koefisiensi Determinasi $\left(R^{2}\right)$}

Koefisiensi determinasi R Square $\left(R^{2}\right)$ pada intinya mengukur seberapa jauh kemampuan model dalam menerangkan variasi variabel dependennya. Nilai koefesien determinan $\left(R^{2}\right)$ yang mendekati satu berarti variabel independennya menjelaskan hamper semua 
informasi yang dibutuhkan untuk memprediksi variabel dependen hasil perhitungan koefisien determinasi penelitian ini dapat dilihat di tabel 6.

Tabel 6.

Koefisien Determinasi $\left(R^{2}\right)$ Model Summaryb

\begin{tabular}{lrrrr}
\hline Model & R & R Square & Adjusted R Square & Std. Error of the Estimate \\
\hline 1 & $.773^{\mathrm{a}}$ & .598 & .568 & .43123
\end{tabular}

a. Predictors: (Constant), IKLAN, CITRA MEREK

b. Dependent Variable: LOYALITAS

sumber : output spss 24 (2018)

Berdasarkan tabel 6 terlihat bahwa dari hasil perhitungan diperoleh nilai ( $R$ Square) sebesar 0.598 adalah pengkuadratan dari koefisien atau $R$, yaitu $0.773 \times 0.773=0.598$. Besarnya angka koefisien determinasi ( $R$ Square) 0.598 sama dengan $59.8 \%$. Angka tersebut mengandung arti Iklan dan Citra Merek, berpengaruh terhadap Loyalitas Pelanggan sebesar $59.8 \%$ sedangkan sisanya $(100 \%-59.8 \%=40.2 \%)$ dipengaruhi oleh variabel lain yang tidak diteliti dalam penelitian ini.

\subsection{Pembahasan Pengaruh masing-masing variabel terhadap loyalitas pelanggan.}

1. Dilihat Dari Nilai Signifikan

1. Variabel Iklan (X1), Berpengaruh secara signifikan terhadap loyalitas pelanggan hal ini dapat dilihat dari bahwa nilai Sig sebesar $0.009<0.05$.

2. Variabel Citra Merek (X2), Tidak berpengaruh secara signifikan terhadap loyalitas pelanggan hal ini dapat dilihat bahwa nilai Sig sebesar $0.301>0.05$.

2. Dilihat Dari Nilai $\mathbf{t}_{\text {hitung }}$

1. Variabel Iklan (X1)

Berpengaruh secara signifikan terhadap loyalitas pelanggan hal ini dapat dilihat dari bahwa nilai $t_{\text {hitung }}$ sebesar $2.715>t_{\text {tabel }}$ sebesar 1.67 .

2. Variabel Citra Merek (X2)

Berpengaruh negative dan secara tidak signifikan terhadap loyalitas pelanggan hal ini dapat dilihat bahwa nilai $t_{\text {hitung }}$ sebesar $1.044<t_{\text {tabel }}$ sebesar 1.67 .

\section{SIMPULAN DAN SARAN}

\subsection{Simpulan}

1. Iklan secara parsial berpengaruh signifikan secara parsial terhadap loyalitas pelanggan pada produk smartphone merek Samsung Galaxy J5 Pro di Pringsewu, Lampung.

2. Citra merek tidak berpengaruh signifikan secara parsial terhadap loyalitas pelanggan pada produk smartphone merek Samsung Galaxy J5 Pro di Pringsewu, Lampung.

3. Iklan dan citra merek secara simultan berpengaruh terhadap variabel loyalitas pelanggan

\subsection{Saran}

Strategi meningkatkan citra merek agar konsumen mempunyai kepercayaan terhadap smartphone merek Samsung adalah dengan cara mengadakan acara di mall-mall semacam lomba atau sponsor, agar konsumen lebih percaya terhadap produk smartphone merek Samsung.

\section{DAFTAR PUSTAKA}

Chaeriah, Ella Siti. 2016. Pengaruh Harga, Citra Merek dan Kualitas Produk Terhadap Loyalitas Pengguna Smartphone Samsung (Studi Pada Mahasiswa Magister Manajemen UNKRIS). Jurnal Manajemen Pemasaran, Vol. 4 No. 3.

Fandy, Tjiptono.2011, Pemasaran Jasa. Malang : Bayumedia.

Griffin, Jill. 2007. Customer Loyalty, Edisi Devisi dan Terbaru. Jakarta : Erlangga. 
Griffin, Ricky W. dan Ebert, Ronald J. 2007. Bisnis. Edisi Delapan. Jilid 1. Jakarta : Erlangga.

Junaedi, Fajar. 2013. Jurnalisme Penyiaran dan Reportase Televisi. Jakarta : Kencana Prenada Media Group.

Kotler, dan Keller. 2012. Manajemen Pemasaran. Edisi 12. Jakarta : Erlangga.

Kotler, Philip \& Armstrong, Garry. 2012. Prinsip-prinsip Pemasaran. Edisi 13. Jilid 1. Jakarta : Erlangga

Kotler, Philip \& Armstrong, Garry. 2013. Prinsip-prinsip Pemasaran. Edisi 12. Jakarta : Erlangga.

Kotler, Philip \& Armstrong, Garry. 2014. Prinsip-prinsip Manajemen. Edisi 14, Jilid 1. Jakarta : Erlangga.

Kuncoro, Mudrajad. 2013. Metode Riset Untuk Bisnis \& Ekonomi. Edisi Keempat. Jakarta : Erlangga.

Lupiyoadi, Rambat dan Ikhsan, Ridho Bramulya. 2015. Praktikum Metode Riset Bisnis, Jakarta : Salemba Empat.

Mamang Sangadji, Etta dan Sopiah, 2010. Metodologi Penelitian. Yogyakarta : Andi.
Panduan Penulisan Skripsi Sekolah Tinggi IImu Ekonomi Mitra Lampung Bandar Lampung 2018.

Sanusi, Anwar. 2012. Metode Penelitian Bisnis. Jakarta : Salemba Empat

Sarjono, Haryadi, And Julianita, Winda. SPSS Vs LISREAL Sebuah Pengantar Aplikasi Untuk Riset . Jakarta : Salemba Empat, 2011.

Sugiyono. 2010. Metode Penelitian Kuantitatif Kualitatif dan R\&D. Bandung : Alfabeta.

Sugiyono. 2011. Statistika Untuk Penelitian. Bandung : Alfabeta.

Sugiyono. 2012. Metodologi Penelitian Bisnis, Cetakan 16. Bandung : Alfabeta.

Sugiyono. 2012. Metode Penelitian Kuantitatif, Kualitatif, dam R\&D. Cetakan ke 17. Bandung : Alfabeta.

Sulianto. 2011. Ekonomika Terapan : Teori dan Aplikasi dengan SPSS. Yogyakarta : ANDI

Terry, George R. dalam Afifudin 2013. Dasardasar Manajemen, (Terje: G.A Ticoalu), CV Alfabeta, Bandung.

Top Brand Award. Diperoleh 05 Juni 2018 dari http://www.topbrand-award.com/topbrand-surveyresult/top_brand_index_2017_fase_1 